\title{
Estimating Productivity of Manufacturing Sector in Shanghai: A Comparative Study ${ }^{1}$
}

\author{
Ying Wang ${ }^{1}$, Yunqing Wang ${ }^{2}, \&$ Wenjie Pan $^{3}$ \\ ${ }^{1}$ World Economy Institute, Shanghai Academy of Social Science, Shanghai China \\ ${ }^{2}$ Institute of Macroeconomy and Strategy, PICC Asset Management Co., Ltd., Shanghai, China \\ ${ }^{3}$ School of Statistics and Information, Shanghai University of International Business and Economics, Shanghai, \\ China \\ Correspondence: Ying Wang, World Economy Institute, Shanghai Academy of Social Science, Shanghai China.
}

Received: August 11, 2020

doi:10.5539/ibr.v13n10p39
Online Published: September 11, 2020

URL: https://doi.org/10.5539/ibr.v13n10p39

\begin{abstract}
The manufacturing sector is the foundation of a nation's industrial structure, and its productivity is closely related to the quality of economic development. The paper uses DEA (Data Envelopment Analysis) models to measure Manufacturing TFP (Total Factor Productivity) and the factors affecting its growth in Shanghai since 1996, and compares Shanghai's TFP growth with other major manufacturing provinces in China. The results show that Shanghai has no significant advantages over other provinces under the combined action of the internal and external factors. Turning to the development mode driven by the "two-wheel" of both technological progress and technical efficiency is an important way to increase the productivity of manufacturing sector in Shanghai.
\end{abstract}

Keywords: manufacturing sector, total factor productivity, Malmquist Index, technical efficiency

\section{Introduction}

Total factor productivity (TFP) is an important indicator to measure the level of productivity and the quality of industrial development. Researchers have used various technical methods to measure manufacturing TFP. For example, the US Bureau of Labor Statistics (BLS, 1983) has tracked the TFP growth of 86 manufacturing sub-industries in the country, using the Tornqvist methodology. OECD (2001) has compared the TFP growth differences among various industries, using growth accounting methodology. The investigation on China's manufacturing TFP shows different results because of different methodologies, also research objects.

Shanghai, as one of the most developing center cities in China and a core city in global competition, has accumulated the operational experiences as long as one hundred years in manufacturing sector and formed the space layout of "one ring, two belts and multiple zones". Under the strategy of accelerating the development of modern service industry in 2008, the output value of Shanghai's manufacturing sector has declined to less than 5\% of the nationwide total value, and the ranking of Shanghai's six pillar sub-industries has been lagging behind other major manufacturing provinces (see figure 1). Furthermore, most of the sub-industries are recession-based ones, and only a few sub-industries can make high profits.

Faced with these problems to be solved, the paper is organized as follows. Section I is literature review. Since the researches on the productivity of manufacturing sector in Shanghai is relatively limited, we extend the vision to the whole country. The views and measurements will give us a more comprehensive observation on Shanghai's manufacturing status in China. Section II explains the methodology employed and the data selected. Considering the consistency of statistical methods and the continuity of data, there are 26 sub-industries included in the study, though there are 31 sub-industries according to "2017 National Economic Industry Classification Notes"2. Section III presents and analyzes the measurement results. We illustrate the results of different sample groups,

${ }^{1}$ Our deepest gratitude goes to the anonymous reviewers for their careful work and thoughtful suggestions that have helped improve this paper substantially.

2 http://www.stats.gov.cn/tjsj/tjbz/201905/t20190522_1666232.html, (accessed September 6 2020). 
that is whole manufacturing sector, the 26 sub-industries and six pillar sub-industries. Furthermore, we compare Shanghai's manufacturing productivity with five leading provinces of manufacturing. Section IV makes a conclusion.

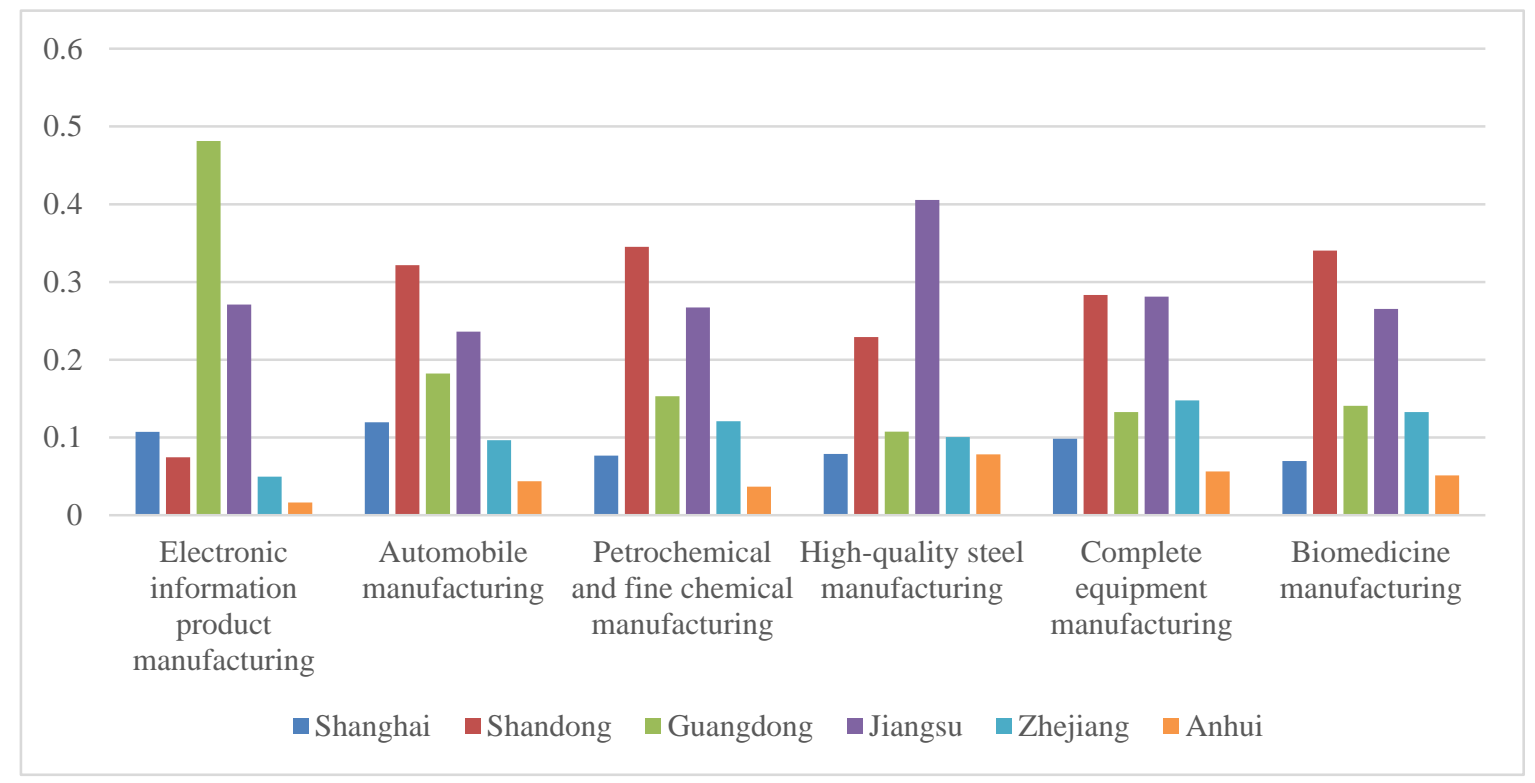

Figure 1. Ranking Comparison between Shanghai’s Six Pillar Sub-industries and Major Manufacturing Provinces from 2005 to 2018

Source: National Statistical Book, 2006-2019.

\subsection{Literature Review}

From a national perspective, Foster-McGregor \& Verspagen (2017) used the World Input-Output Database and calculated TFP growth in manufacturing and services for a sample of 40 economies during the period 1995-2009. In China, the average annual TFP growth in manufacturing is $88.85 \%$, which is higher than in service. Wang (2018) measured China's manufacturing TFP during the period 1996-2013 with OP, LP, GMM and FE methods, and found that TFP growth was in the range of $3.9 \%$ to $18.94 \%$ and showed a certain convergence trend. Turning to the period from 2002 to 2017, the TFP growth increased first and then deceased from a 2007 peak of $13.9 \%$ (Li et al.,2020). Zhao \& Gu (2018) compared the manufacturing development quality gap between China and the United States from three perspectives such as productivity in manufacturing process, the capability of value acquisition in export trade link, and technology content. Studies show the gap between two countries has been widening after the 2008 financial crisis. The overall growth of manufacturing TFP in China was $39.89 \%$ of that of the United States in 2014, and the growth of computer, electronic and optical products was only $29.53 \%$. Similar findings have been made in the studies of the correlation between industries TFP and economic growth momentum in China (Xu et al., 2020). Before the global financial crisis, China's manufacturing sector was not only the engine of economic growth, but also the driving industry of efficiency improvement, especially the manufacturing of those downstream and export-oriented finished and semi-finished products.

At regional level, the average TFP growth of manufacturing sector in Northeast China reached $20.2 \%$ during the period 1999-2005, which was the highest among the six regions in China (Yang \& Wang, 2008). Results of Liu's (2020) TFP measurement of 7 sub-industries in equipment manufacturing in Northeast China in the period 2003-2016 show that most sub-industries have not formed scale effects and the technical efficiency has been declining, although TFP was on the rise. Shi \& Zhou (2014) used Malmquist Index method and concluded that the TFP growth of manufacturing sector in China's eastern region was mainly driven by technological progress, while the growth in central and western regions were brought out by the improvement of technical efficiency from 2003-2011. Li et al. (2020) found with Solow Residual method that the manufacturing TFP in western and central regions improved significantly during the period 2002-2017, while changed little in northeastern region and declined in eastern region. 
At provincial level, Shi \& Yao (2011) investigated 31 sub-industries in Shanghai from 2004 to2008 based on DEA research. They indicated that most sub-industries couldn't achieve technology and scale efficiency simultaneously, furthermore both kinds of efficiencies went worse in the past five years. Gao (2011) calculated the TFP of various sub-industries in Guangdong Province in the period 2000-2007 based on Malmquist index. The results show that growth was mainly sourced from technological progress, and technical efficiency did not change much in the manufacturing powerhouse of Guangdong. As for Jiangsu province, which is famous for its strong manufacturing sector, its average growth of manufacturing TFP in the period 2011-2016 was negative, and there was a significant gap among different sub-industries (Zhao \& Wei, 2020). A contrast is Anhui, which is a traditional agriculture province. Its manufacturing TFP of 31 sub-industries has been continuously improved during the period 2003-2016 (Jiang et al., 2019).

Scholars have analyzed the factors affecting the productivity of manufacturing sector in China. Qiu (2008) found that R\&D and export delivery value have a positive effect on TFP. Qian et al. (2011) believed that the types of imports had different effects on the TFP growth. Chen \& Xu (2012) found every $1 \%$ increase in the scale of the local market would promote a productivity index increase of $0.021 \%$. Jin(2018) indicated that government subsidies caused resource misallocation among enterprises, and the resource misplacement had a negative effect on manufacturing productivity. His views are consistent with Prescott's (1998) findings 20 years ago. Prescott pointed out if there are decentralized arrangements with resource allocation and decision-making authorities, technological progress will continue and TFP will increase. Since finance is the blood of real economy, the mismatch of financial resources has a significant inhibitory effect on the improvement of manufacturing TFP, especially in SOEs (Wang \& Cao, 2019).

Looking future, manufacturing sector is still vital to the sustainable development of Shanghai's entire economy, though the proportion of service industry has exceeded $70 \%$ of the municipality's GDP. To this end, this paper intends to solve two key issues. One is to measure the TFP growth of Shanghai's manufacturing as a whole, various sub-industries and the six pillar sub-industries; the other is to compare Shanghai's manufacturing productivity with that of other five major manufacturing provinces in China.

\section{Research Methodology}

The paper uses the data envelopment analysis based on Malmquist index methodology, which comprehensively analyzes input and output data, and studies TFP using non-parametric method. The advantage is that it does not need to pre-set the form of the production function.

\subsection{Research Methods}

As a non-parametric method, Data Envelopment Analysis (DEA) calculates the frontier of production technology through mathematical programming theory, and then evaluates production efficiency. In terms of TFP measurement, the DEA method based on Malmquist index is widely used. The Malmquist index is the ratio of the distance function (Liu \& Zhang, 2010). It calculates each decision-making unit's distance from the production frontier in period $t$ and period $t+1$ based on input-output data, representing the change of productivity in the two periods, and then solves the distance function by DEA method, so as to obtain the relative efficiency change, i.e. TFP growth.

According to the study of Fare et al. (1994), the Malmquist TFP change index (TFPch) can be expressed as:

$$
M_{0}\left(x^{t+1}, y^{t+1}, x^{t}, y^{t}\right)=\left[\left(\frac{D_{0}^{t}\left(x^{t+1}, y^{t+1}\right)}{D_{0}^{t}\left(x^{t}, y^{t}\right)}\right)\left(\frac{D_{0}^{t+1}\left(x^{t+1}, y^{t+1}\right)}{D_{0}^{t+1}\left(x^{t}, y^{t}\right)}\right)\right]^{1 / 2}
$$

In which, $D_{0}^{t}\left(x^{t}, y^{t}\right)$ and $D_{0}^{t}\left(x^{t+1}, y^{t+1}\right)$ respectively represent the output distance function obtained by comparing $\left(x^{t}, y^{t}\right)$ and $\left(x^{t+1}, y^{t+1}\right)$ with the cutting-edge technology in period $\mathrm{t} ; D_{0}^{t+1}\left(x^{t}, y^{t}\right)$ and $D_{0}^{t+1}\left(x^{t+1}, y^{t+1}\right)$ respectively represent the output distance function obtained by comparing $\left(x^{t}, y^{t}\right)$ and $\left(x^{t+1}, y^{t+1}\right)$ with the cutting-edge technology in period $t+1$. The Malmquist index reflects the TFP change at production point $\left(x^{t+1}, y^{t+1}\right)$ relative to production point $\left(x^{t}, y^{t}\right)$. If the index value is greater than 1 , it indicates that the TFP change at the production point is positive growth.

Furthermore, the Malmquist TFP change index can be decomposed into technical efficiency change (effch) and technological change (techch), namely: 


$$
M_{0}\left(x^{t+1}, y^{t+1}, x^{t}, y^{t}\right)=\frac{D_{0}^{t+1}\left(x^{t+1}, y^{t+1}\right)}{D_{0}^{t}\left(x^{t}, y^{t}\right)}\left[\left(\frac{D_{0}^{t}\left(x^{t+1}, y^{t+1}\right)}{D_{0}^{t+1}\left(x^{t+1}, y^{t+1}\right)}\right)\left(\frac{D_{0}^{t}\left(x^{t}, y^{t}\right)}{D_{0}^{t+1}\left(x^{t}, y^{t}\right)}\right]^{1 / 2}\right.
$$

In which, $D_{T E}^{t+1}\left(x^{t+1}, y^{t+1}, x^{t}, y^{t}\right)=\frac{D_{0}^{t+1}\left(x^{t+1}, y^{t+1}\right)}{D_{0}^{t}\left(x^{t}, y^{t}\right)}$ is technical efficiency change, and the ratio of resource allocation efficiency in period $t+1$ to that in period $t$. It has nothing to do with the change of technical level, and represents the change of production resource allocation levels in the two periods. $D_{T C}^{t+1}\left(x^{t+1}, y^{t+1}, x^{t}, y^{t}\right)=\left[\left(\frac{D_{0}^{t}\left(x^{t+1}, y^{t+1}\right)}{D_{0}^{t+1}\left(x^{t+1}, y^{t+1}\right)}\right)\left(\frac{D_{0}^{t}\left(x^{t}, y^{t}\right)}{D_{0}^{t+1}\left(x^{t}, y^{t}\right)}\right)\right]^{1 / 2}$ is technological change, reflecting the change of optimal technologies in period $\mathrm{t}+1$ and period $\mathrm{t}$.

In the case of variable returns to scale (VRS), technical efficiency change can be further decomposed into pure technical efficiency change (pech) and scale efficiency change (sech), namely:

$$
D_{T E}^{t+1}\left(x^{t+1}, y^{t+1}, x^{t}, y^{t}\right)=\frac{D_{0}^{t+1}\left(x^{t+1}, y^{t+1}\right)}{D_{0}^{t}\left(x^{t}, y^{t}\right)}=\frac{s_{0}^{t}\left(x^{t}, y^{t}\right)}{s_{0}^{t}\left(x^{t+1}, y^{t+1}\right)} \frac{D_{0}^{t}\left(x^{t+1}, y^{t+1} / V R S\right)}{D_{0}^{t}\left(x^{t}, y^{t} / V R S\right)}
$$

In which, $\frac{s_{0}^{t}\left(x^{t}, y^{t}\right)}{s_{0}^{t}\left(x^{t+1}, y^{t+1}\right)}$ is pure technical efficiency change. If the pure technical efficiency change is greater than 1 , it indicates that improved management has improved efficiency. $\frac{D_{0}^{t}\left(x^{t+1}, y^{t+1} / V R S\right)}{D_{0}^{t}\left(x^{t}, y^{t} / V R S\right)}$ is scale efficiency change. If the scale efficiency change is greater than 1 , it indicates that the change of factor input has improved the scale efficiency.

According to the above decomposition, the Malmquist TFP change index can be expressed as

$$
\begin{gathered}
M_{0}\left(x^{t+1}, y^{t+1}, x^{t}, y^{t}\right) \\
=\frac{s_{0}^{t}\left(x^{t}, y^{t}\right)}{s_{0}^{t}\left(x^{t+1}, y^{t+1}\right)} \frac{D_{0}^{t}\left(x^{t+1}, \frac{y^{t+1}}{V R S}\right)}{D_{0}^{t}\left(x^{t}, \frac{y^{t}}{V R S}\right)}\left[\left(\frac{D_{0}^{t}\left(x^{t+1}, y^{t+1}\right)}{D_{0}^{t+1}\left(x^{t+1}, y^{t+1}\right)}\right)\left(\frac{D_{0}^{t}\left(x^{t}, y^{t}\right)}{D_{0}^{t+1}\left(x^{t}, y^{t}\right)}\right)\right]^{1 / 2}
\end{gathered}
$$

The four distance functions in formula (4) can be solved by the DEA method, namely:

$$
\begin{gathered}
{\left[D_{0}^{t}\left(x^{q, t}, y^{q, t}\right)\right]^{-1}=\max \theta^{q}} \\
\text { s.t. } \theta^{q} y_{m}^{q, t} \leq \sum_{q=1}^{Q} z^{q, t} y_{m}^{q, t} \\
x_{m}^{q, t} \geq \sum_{q=1}^{Q} z^{q, t} y_{m}^{q, t} \\
z^{q, t} \geq 0
\end{gathered}
$$




$$
\begin{aligned}
& {\left[D_{0}^{t+1}\left(x^{q, t}, y^{q, t}\right)\right]^{-1}=\max \theta^{q}} \\
& \text { s.t. } \theta^{q} y_{m}^{q, t} \leq \sum_{q=1}^{Q} z^{q, t+1} y_{m}^{q, t+1} \\
& x_{m}^{q, t} \geq \sum_{q=1}^{Q} z^{q, t+1} y_{m}^{q, t+1} \\
& z^{q, t+1} \geq 0 \\
& {\left[D_{0}^{t}\left(x^{q, t+1}, y^{q, t+1}\right)\right]^{-1}=\max \theta^{q}} \\
& \text { s.t. } \theta^{q} y_{m}^{q, t+1} \leq \sum_{q=1}^{Q} z^{q, t} y_{m}^{q, t} \\
& x_{m}^{q, t+1} \geq \sum_{q=1}^{Q} z^{q, t} y_{m}^{q, t} \\
& z^{q, t} \geq 0 \\
& {\left[D_{0}^{t+1}\left(x^{q, t+1}, y^{q, t+1}\right)\right]^{-1}=\max \theta^{q}} \\
& \text { s.t. } \theta^{q} y_{m}^{q, t+1} \leq \sum_{q=1}^{Q} z^{q, t+1} y_{m}^{q, t+1} \\
& x_{m}^{q, t+1} \geq \sum_{q=1}^{Q} z^{q, t+1} y_{m}^{q, t+1} \\
& z^{q, t+1} \geq 0
\end{aligned}
$$

In this linear programming, $Q$ decision-making units are included. $x^{q, t}$ and $y^{q, t}$ respectively represent the input and output of decision-making unit $q$ in period $t .1 / \theta$ is technical efficiency; $z^{q, t}$ represents the weight of decision-making unit $q$ in period $t$.

\subsection{Data Selection}

Data used in the paper is sourced from Shanghai Statistical Yearbook (1995-2019), and the data selected is as follows:

Output variable: The total industrial output value of each manufacturing sub-industries is taken as output.

Input variable: including capital input and human input. The total assets of the industry at the end of the year are taken as capital input, and the number of employees is taken as human input.

In order to use actual value indicators for research, value economic indicators (output and capital inputs) should be deflated. Output indicators are deflated using the producer price index of industrial products, and capital input is deflated using the price index of investment in fixed assets. The base period for the deflator is 2000 .

The samples in the paper can be divided into 1 full sample and 1 sub-sample. Firstly, the full sample is sub-industries divided by industries of the national economy, and the sample interval is 1995-2018. Excluding some industries whose statistical standards have changed, 26 sub-industries are ultimately retained. Secondly, the sub-sample is the six pillar sub-industries in Shanghai, and the sample interval is 2001-2019. 


\section{Research and Analysis Results}

This paper measures TFP from three levels such as manufacturing sector as a whole, 26 sub-industries, and six pillar sub-industries. At the same time, the paper makes a comparative analysis with Shandong, Guangdong, and other provinces in the Yangtze River Delta, including Anhui, Jiangsu and Zhejiang.

\subsection{Shanghai's Overall Manufacturing TFP and Comparative Analysis}

Shanghai's manufacturing TFP growth showed a trend of wide fluctuations, as shown in Figure 2. The growth fell steadily at the end of the last century, and showed a significant drop in 1999 affected by the 1997 Asian financial crisis and the reform of SOEs together. In 2000, Shanghai Municipal Government selected six most powerful industries as the strategic pillars, and successively introduced a series of supporting policies. Thanks to the "luck" access to WTO, Shanghai's manufacturing TFP growth rose sharply and reached 14\% in 2000, which was the highest rate in the past twenty years. Then, the sector experienced an eight-year period of medium and high-speed growth, and the annual average rate was $8.2 \%$. The outbreak of the 2008 financial crisis led to a contraction of the global supply chain. Shanghai's manufacturing TFP growth turned negative in 2009. Driven by the introduction of the "four trillion" fiscal stimulus plan and other rescue policies, the TFP growth recovered in 2010-2011 with the domestic demand rebounded and industrial situation bettered. Later, due to the decline in both domestic and foreign demand and the reduction in the proportion of Shanghai's manufacturing sector, the productivity continued to glide down until 2016. Under the influence of China's supply-side structural reform, the growth rate achieved $5.51 \%$ in 2017 and $3.19 \%$ in 2018 respectively.

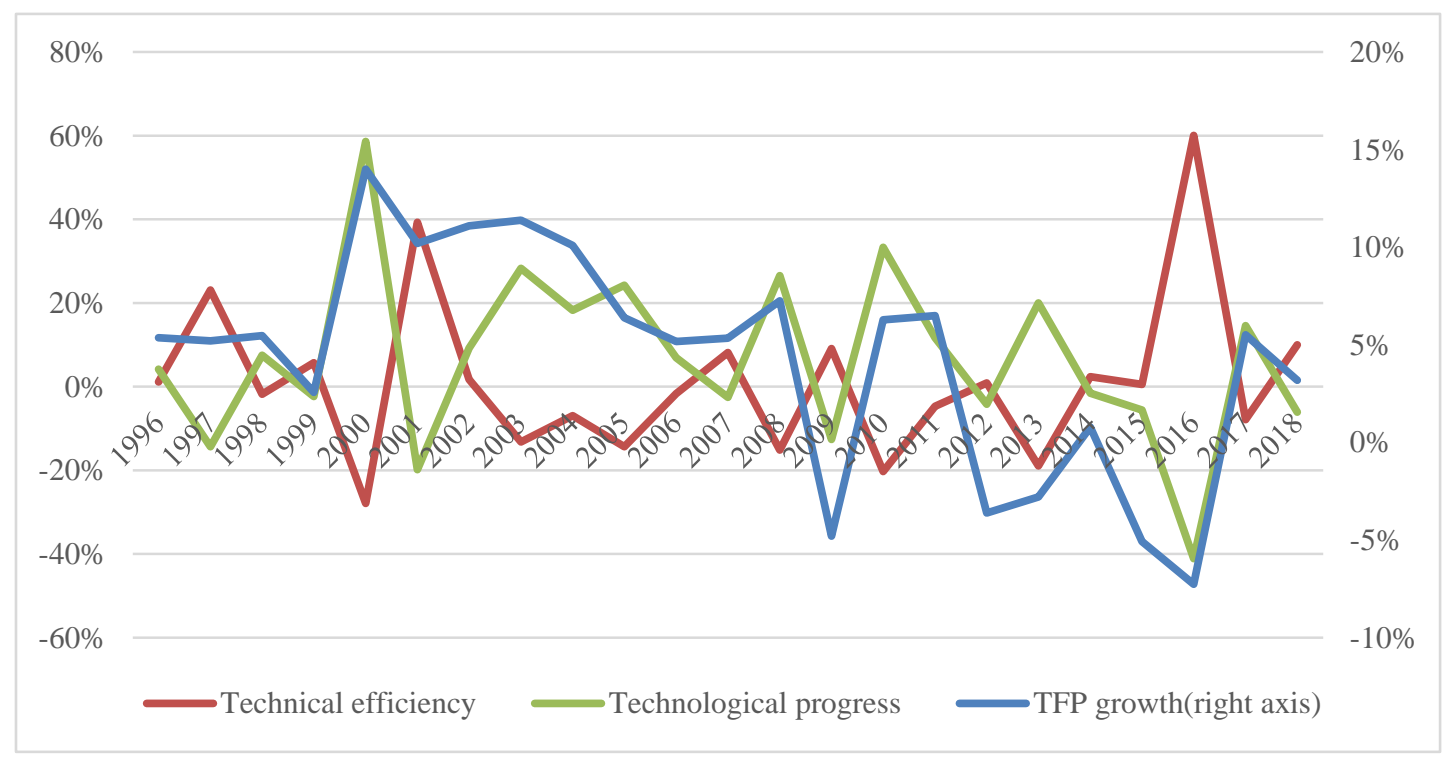

Figure 2. Shanghai's manufacturing TFP growth and its two decomposition factors in 1996-2018

Source: Self-calculated based on the data from Shanghai Statistical Yearbook

As for the contributing factors of manufacturing productivity, they are generally divided into technological progress and technical efficiency. The economic meaning of technological progress refers to the increase in output only due to technological improvement on the premise that the input of production factors remains unchanged. The increase in output includes direct technical factors such as advanced technology, technological innovation, patents, and high-tech equipment, as well as non-technical factors such as management level, entrepreneurial ability, system reform, business cycle, etc. It is called "growth effect" and "divergence effect". Technical efficiency reflects the gap between the actual output level and the production frontier (the largest potential output), so it is also called "horizontal effect" or "catch-up effect". If most of the enterprises in the industry cannot keep up with the advancement of cutting-edge technologies, the technological efficiency gap between enterprises will widen, also the overall technical efficiency of the industry will decline. Conversely, if most enterprises can follow up in time when the industry's cutting-edge technologies move forward, the overall technical efficiency will be improved.

In the period 1996-2018, technological progress contributed an average of $7.2 \%$ to Shanghai's manufacturing 
TFP growth, which was even higher than the $4.3 \%$ growth rate of TFP itself. The result shows that Shanghai's manufacturing industry has done relatively well in absorbing advanced technologies, high-tech equipment, management experiences and all kinds of professionals, as well as in maintaining the cutting-edge technology. The production frontier led by Shanghai as a national advanced manufacturing municipality has kept outward expansion and gotten obvious "growth effect" and "divergence effect". The average growth of technical efficiency is only $0.9 \%$. After technical efficiency is further decomposed into pure technical efficiency and scale efficiency, it is found that the former has achieved an average annual growth of $0.5 \%$ and the latter is $0.6 \%$. On the whole, the "growth effect" contributed by the technological progress is significant, which means the technological progress is the main driving force for Shanghai's manufacturing productivity. The "catch-up effect" contributed by technical efficiency is relatively limited, indicating that there is still large space for improvement.

We further compare Shanghai's productivity with that of Shandong, Guangdong and the other three manufacturing provinces (that is Anhui, Jiangsu and Zhejiang) in the Yangtze River Delta. It is found that the fluctuation trend of each province (or municipality) is generally the same. In the early period (2006-2011), Shanghai's manufacturing TFP growth was in the middle position, while in the middle period (2012-2016), the growth remained negative and ranked low. In recent period (since 2017), the growth has improved and exceeded that of provinces such as Shandong and Guangdong. See Figure 3.

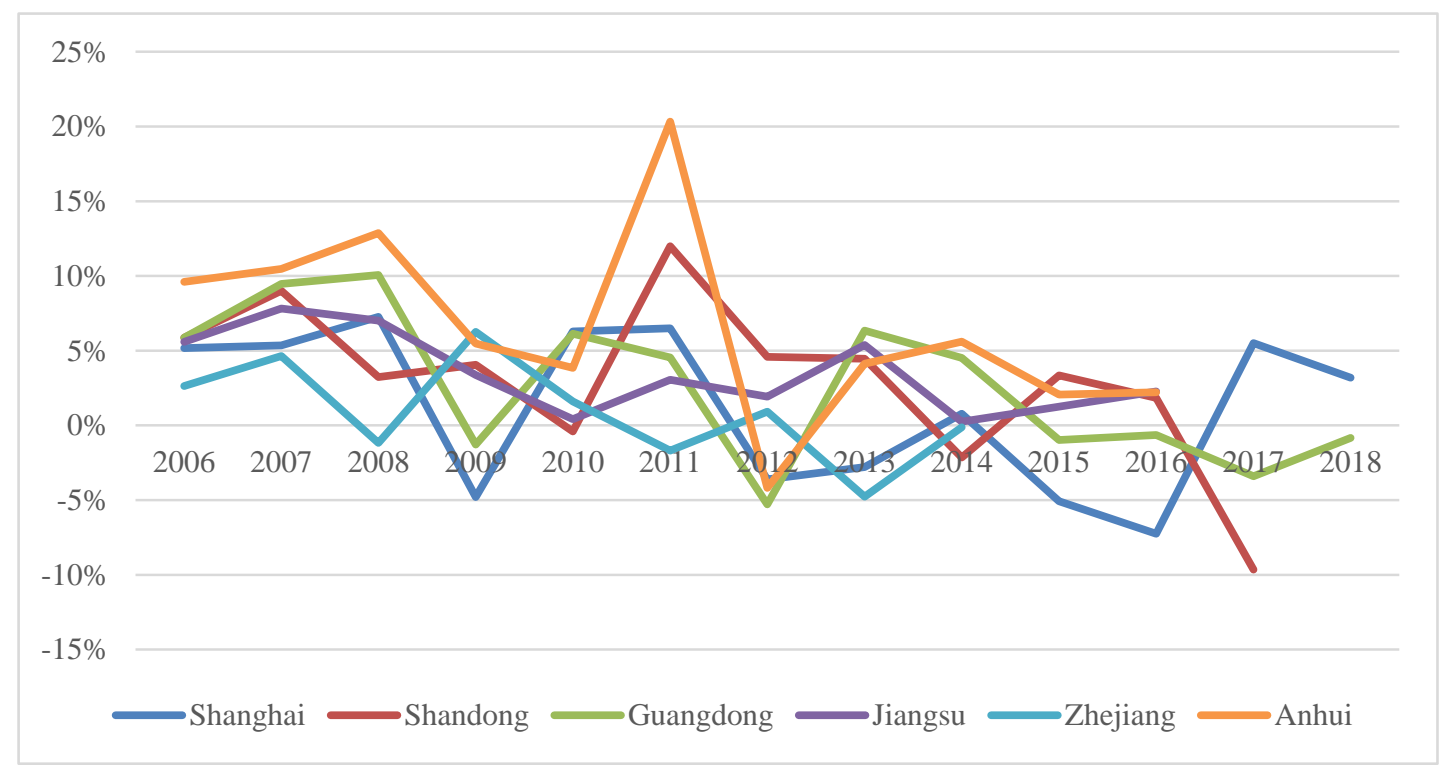

Figure 3. Comparison of manufacturing TFP growth in Shanghai and some provinces in 2006-2018

Source: Self-calculated based on the data from Shanghai Statistical Yearbook

\subsection{TFP of Shanghai's 26 Manufacturing Sub-Industries and Comparative Analysis}

A comparison of the average TFP growth trend of Shanghai's 26 manufacturing sub-industries is shown in Figure 4. The results show that TFP growth varies greatly among different sub-industries, and the growth is seriously unbalanced. The top three sub-industries with the highest average TFP growth in 1996-2018 were tobacco processing $(15.3 \%)$, ferrous metal smelting and rolling processing $(12.1 \%)$, petroleum, coal and other fuel processing $(10.0 \%)$, all with a growth of over $10 \%$. There are only three sub-industries with an average TFP growth ranging from $5 \%$ to $10 \%$, namely computer, communications and other electronic equipment (7.8\%), culture and education, arts and crafts, sports and entertainment products manufacturing (6.3\%), and non-ferrous metal smelting and rolling processing (5.3\%). There are 20 sub-industries with an average TFP growth lower than 5\%, which account for $77 \%$ of Shanghai's manufacturing sector. Three sub-industries with the lowest ranking are leather, fur, feathers and their products and footwear $(0.7 \%)$, textiles, garment and apparel (1.6\%), and pharmaceutical manufacturing $(1.7 \%)$. The existence of a large number of low-growth sub-industries has reduced the average TFP growth of the whole manufacturing sector (4.3\%). 


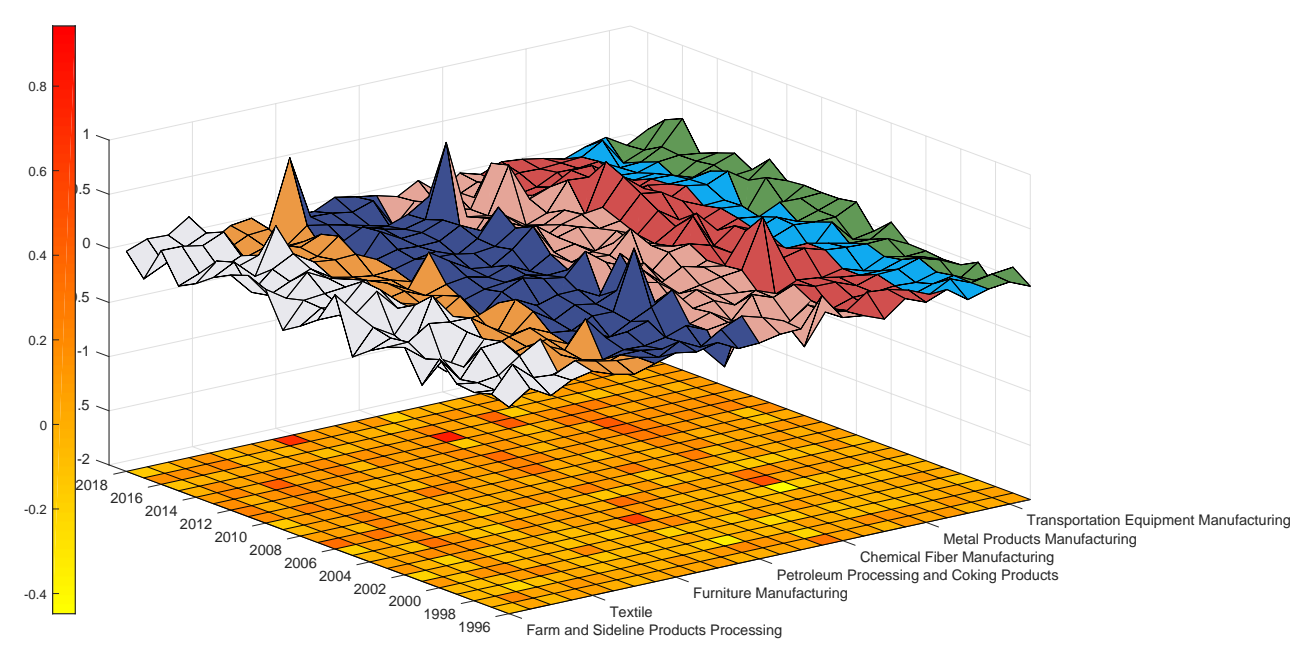

Figure 4. Comparison of TFP growth of Shanghai's 26 manufacturing sub-industries in 1996-2018

Source: Self-calculated based on the data from Shanghai Statistical Yearbook

As for the contribution factors, each sub-industry is basically driven by technological progress, and the average growth of technological progress is more than $5.5 \%$. The top three sub-industries are tobacco processing (15.3\%), ferrous metal smelting and rolling processing (12.5\%), petroleum, coal and other fuel processing (10.0\%). The average growth of technical efficiency has heavy disparity, with the highest average growth in culture and education, arts and crafts, sports and entertainment products manufacturing (4.4\%), and the lowest in chemical fiber manufacturing (-1.5\%). See Table 1 for details. Except for computer et al. manufacturing and culture \& education et al. manufacturing, all the other 24 sub-industries are single-wheel driven, that is technological progress.

We further compare the average TFP growth of 26 sub-industries in Shanghai and other provinces. Due to factors such as the continuous decline in the proportion of Shanghai's manufacturing industry, the average TFP growth of Shanghai is only higher than that of Zhejiang. The average TFP growth of Anhui is the highest, reaching $6.58 \%$, which is five times that of Shanghai. Specifically, tobacco processing, petroleum, coal and other fuel processing, and ferrous metal smelting and rolling processing are the three sub-industries with the fastest average TFP growth in Shanghai and most provinces. See Table 2.

\subsection{TFP and Comparative Analysis of Six Pillar Industries in Shanghai}

The six pillar sub-industries in Shanghai are known as "six golden flowers". They have been the dominant industries of the manufacturing sector and been supported by Shanghai government, including electronic information products, automobile, petrochemical and fine chemical products, high-quality steel, complete equipment, and biomedicine manufacturing.

The overall average TFP growth of six pillar sub-industries is 5.53\%, which is higher than $3.3 \%$, the growth of manufacturing as a whole, indicating that the pillars have indeed played a leading role in promoting the development of Shanghai's manufacturing. The TFP growth difference among different pillars is obvious. The highest average growth is in high-quality steel manufacturing (11.9\%), and the lowest is in biomedicine manufacturing (1.6\%). The large difference of $10 \%$ refers to the progress and development between sub-industries is extremely uneven. From the perspective of the contribution factors, the TFP growth trend of the six pillars is similar to the path of technological progress, and deviates from technical efficiency, which indicates that the six pillars mainly rely on the "diffusion effect" of cutting-edge technological progress to promote TFP growth, and there is much room for the improvement of the "catch-up effect" of technical efficiency. See Figure 4. 


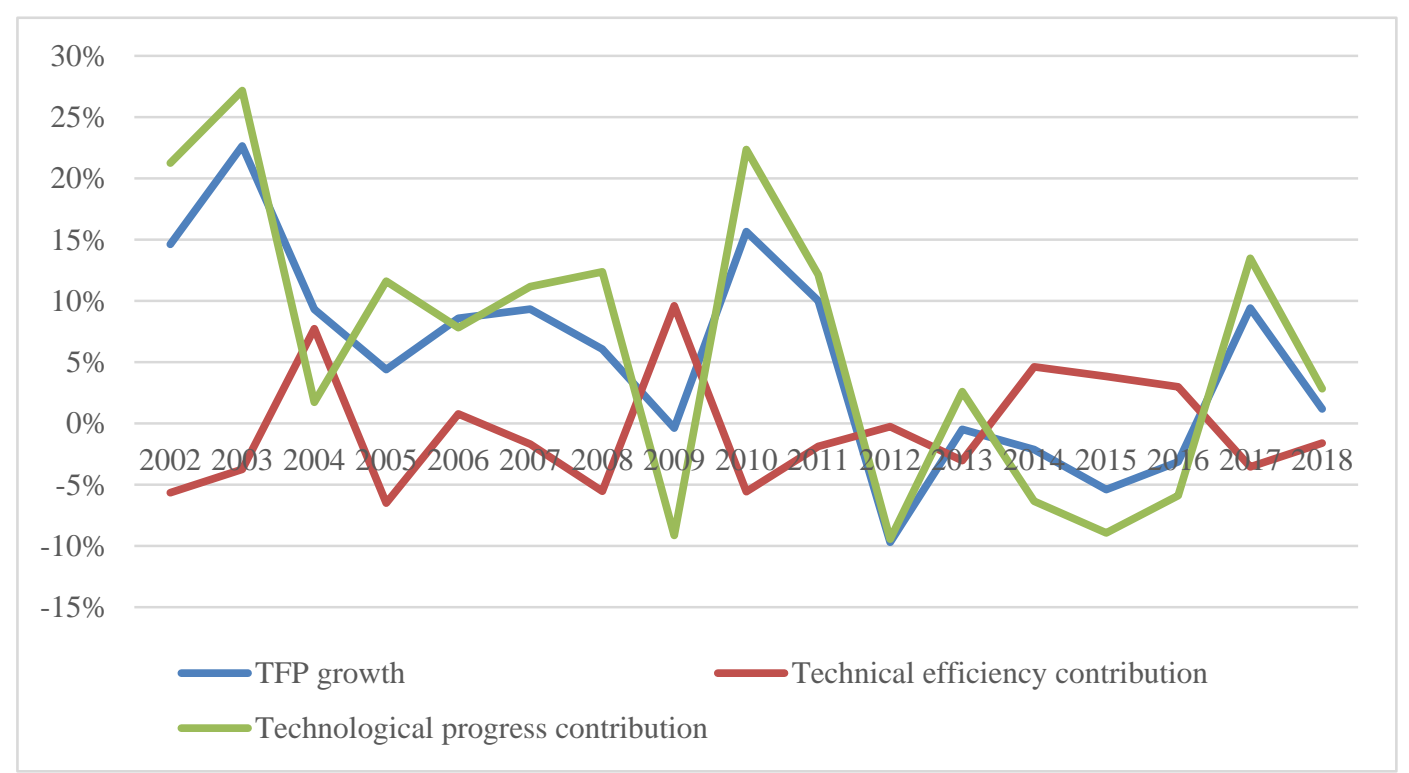

Figure 4. TFP growth and factor contribution of six pillar sub-industries in Shanghai in 2002-2018

Source: Self-calculated based on the data from Shanghai Statistical Yearbook

From the perspective of contribution factors, the TFP growth of biomedicine manufacturing is dragged down by technical efficiency, and the main reason is the decline in scale efficiency. Automobile and complete equipment also have the same feature, indicating that the above three sub-industries have obvious "diffusion effect", but relatively limited "catch-up effect". Although the average TFP growth of high-quality steel manufacturing is greater than $10 \%$, almost all of it comes from the contribution of technological progress. The contribution of technical efficiency is close to zero. It seems that the high-quality steel manufacturing is a typical example of "single-wheel driven" industry, and the conclusion is also applicable for electronic information sub-industry. Petrochemical and fine chemical manufacturing is the only sub-industry with positive growth both in technological progress and technical efficiency, but the latter's growth is far lower than the former's. The sub-industry must make more efforts on how to balance the relation of two contribution factors. See Table 3.

For 17 years or longer, the six pillar sub-industries which should set a good example of balanced and sustainable development for other sub-industries, have been in a growth mode of technical inefficiency and "single-wheel" driven processing. If this continues for too long, it may inevitably bring a serious threat to the health development both of Shanghai's manufacturing sector and macro-economy.

Since other provinces have not classified the six pillar industries like Shanghai, we intend to analyze relevant industries in comparison. The average TFP growth of Shanghai's automobile and high-quality steel ranks higher compared with other provinces. The growth of petrochemical and fine chemical manufacturing is at an upper-middle level, while the growth of electronic information products, biomedicine manufacturing, and complete equipment is lower than the average of six sub-industries. Anhui province has a leading position in the above three sub-industries. See Table 2.

\section{Basic Conclusion}

The paper uses data envelopment analysis based on Malmquist index to study the productivity of manufacturing sector and its sub-industries in Shanghai. The study shows that the TFP growth of sub-industries in Shanghai fluctuated widely from 2002 to 2018. Although Shanghai has six pillar sub-industries designed with a leading role, it has no significant advantage compared with other manufacturing provinces. The unexpected result is mainly attributed to the fact that the high-quality development mode driven by "two-wheel" of technological progress and technical efficiency has not yet formed in Shanghai. The basic conclusions are as follows:

Firstly, Shanghai's manufacturing TFP growth has experienced a wide fluctuation due to the external environment and internal development mode, and the municipality leads the national manufacturing sector alternately with other five manufacturing provinces. During the period from 1996 to 2018, the TFP growth of Shanghai's manufacturing industry sector showed negative in five years, and it was above $10 \%$ in four years and between 0 and $10 \%$ in other years. Compared with other five provinces, Shanghai's manufacturing TFP growth 
was in the middle position during 2006-2011, lagging behind Anhui and Guangdong. In the period 2012-2016, the growth significantly lagged behind Guangdong, Shandong, Jiangsu and Anhui. In 2017, the productivity in Shanghai manufacturing sector improved and surpassed that of Shandong and Guangdong.

Secondly, the average annual TFP growth varies greatly among Shanghai's 26 manufacturing sub-industries, which is less advantageous than other provinces. There are 20 sub-industries with an average annual TFP growth of below 5\%, accounting for $77 \%$ of total sector. At the same time, none of the sub-industries in Shanghai has the highest average annual growth among the six provinces or municipality investigated. The highest TFP growth of tobacco processing is in Zhejiang, which is as high as $14.04 \%$; the highest TFP growth of petroleum, coal and other fuel processing is in Guangdong, which is as high as $6.94 \%$; the highest TFP growth of ferrous metal smelting and rolling processing is in Anhui, which is as high as $7.22 \%$. Among the other 23 sub-industries, Shanghai has no sub-industry with the highest average annual growth.

Thirdly, Shanghai's "six golden flowers" have played some certain leading role, but their average annual TFP growth has no significant advantage over other provinces. The provinces with the highest TFP growth in electronic information product are Anhui and Shandong. Anhui and Jiangsu are the leading provinces in terms of TFP growth of biomedicine and complete equipment manufacturing.

Fourthly, the main factor restricting Shanghai's manufacturing TFP growth is that the high-quality development mode driven by "two-wheel" of technological progress and technical efficiency has not yet formed. On the whole, the average annual growth of technological progress reached 7.2\% during 1996-2018, which was even higher than the $4.3 \%$ growth of TFP over the same period, and the average annual growth of technical efficiency was only $0.9 \%$. It can be seen that the single-wheel drive mode that mainly relies on technological progress to improve TFP has become a hindrance to the high-quality development of Shanghai's manufacturing sector.

\section{References}

Chen F. L., \& Xu, K. N. (2012). Scale of the Local Market and China's Manufacturing TFP. China Industrial Economy (Zhongguo Gongye Jingji), 5, 44-56.

Fare, R., Grosskopf, S., \& Norris, M., et al. (1994). Productivity Growth, Technical Progress, and Efficiency Change in Industrialized Countries. American Economic Review, 84(1), 66-83.

Foster-McGregor, N., \& Verspagen, B. (2017). Decomposing Total Factor Productivity Growth in Manufacturing and Services. Asian Development Review, 34(1), 88-115. https://doi.org/10.1162/ADEV_a_00082

Gao, S. (2011). Total Factor Production of Guangdong's Manufacturing Industry-based on Panel Data for 2000-2007. China Urban Economy (Zhongguo Chengshi Jingji), 5, 35-38.

Jiang, J. Y., Ding, T. Y., \& Zhang, Q. X. (2018). Research on TFP of Manufacturing Industry in Anhui Province and Its Influencing Factors. Journal of Qiqihar University ( Qiqi Haer Xuebao), 9, 63-77.

Jin, X. Y. (2018). Government Subsidies, Resource Misplacement and Manufacturing Productivity. Finance \& Trade Economics (Caimao Jingji), 6, 43-57.

Li, Y. H., Shi, L. Y., \& Li, Y. (2020). Measurement and Comparison of China's Manufacturing TFP Growth. On Economic Problems (Jingji Wenti), 3, 83-91.

Liu, B. B. (2020). TFP Measurement of Equipment Manufacturing Industry in Northeast China and Research on its Improvement Path. Economic Review (Jingji Zongheng), 1, 106-112.

Liu, X. K., \& Zhang, C. (2010). China's Service Industry TFP Growth and its Convergence Analysis. Quantitative \& Technical Economics (Shuliang Jingji Jishu Jingji Yanjiu), 27(3), 55-67+95.

OECD. (2001). Measuring Productivity OECD Manual: Measurement of Aggregate and Industry-level Productivity Growth. Paris: OECD.

Prescott, E. C. (1998). Needed: A Theory of Total Factor Productivity. International Economic Review, 39(3), 525-551. https://doi.org/10.2307/2527389

Qian, X. F., Wang, S., \& Huang, Y. H. (2011). Import Types and China's Manufacturing TFP. World Economy (Shijie Jingji), 5, 3-25.

Qiu, B., Yang, S., \& Xin, P. J. (2008). Research on FDI Technology Spillover Channels and China's Manufacturing Productivity: Analysis based on Panel Data. World Economy (Shijie Jingji), 8, 20-31.

Shi, L., \& Yao, H. Z. (2011). Technical Advance, Efficiency and Scale Adjustment of Manufacturing in Shanghai: Based on DEA Research. Journal of Shanghai Economy Research (Shanghai Jinji Yanjju), 12, 15-24. 
US Bureau of Labor Statistics. (1983). Trends in Multifactor Productivity, 1948-1981. Bulletin 2178, USGPO, Washington D. C.

Wang, G. D. (2018). TFP Calculation of Chinese Manufacturing Enterprises in 1996-2013. China Economic Studies (Zhongguo Jingji Wenti), 7, 88-99.

Wang, X., \& Cao, H. P. (2019). Effect of Financial Resource Misallocation on TFP of China's Manufacturing Enterprises. Journal of Finance \& Trade Research (Caimao Yanjiu), 9, 43-53.

Xu, X. C., Zhang, Z. W., Chang, Z. H., \& Lei, Z. K., (2020). Industrial Productivity and Economic Growth Drivers in China. Journal of World Economy (Shijie Jingji), 2, 25-49.

Yang, G. Y., \& Wang, L. L, (2008). Technological Progress, Technical Efficiency and Regional Difference of Provincial Manufacturing Industry: Empirical Research based on DEA. Journal of Technology Economics (Jishu Jingji), 1, 110-115.

Zhao, M., \& Wei, X. (2020). Research on Multi-dimensional Measurement and Evaluation of Total Factor Productivity of Jiangsu Manufacturing. Science \& Technology and Economy (Keji Yu Jingji), 2, 102-105.

Zhao, Y. L., \& Gu, J. J. (2018). Measurement and Comparative Research on the Development Quality of Manufacturing Industries in China and the United States. Quantitative \& Technical Economics (Shuliang Jingji Jishu Jingji Yanjiu), 12, 116-133. 


\section{Appendix}

Table 1. Average TFP growth and its decompositions of each manufacturing sub-industry in 1996-2018

\begin{tabular}{|c|c|c|c|c|c|}
\hline Industry & EC & TC & PEC & SEC & TFP \\
\hline Non-staple food processing & $-0.4 \%$ & $6.4 \%$ & $-0.3 \%$ & $-0.2 \%$ & $1.9 \%$ \\
\hline Food manufacturing & $1.3 \%$ & $6.6 \%$ & $0.1 \%$ & $0.6 \%$ & $3.7 \%$ \\
\hline Liquor, beverage and refined tea manufacturing & $-0.5 \%$ & $7.4 \%$ & $0.0 \%$ & $-0.2 \%$ & $3.1 \%$ \\
\hline Tobacco processing & $0.0 \%$ & $15.3 \%$ & $0.0 \%$ & $0.0 \%$ & $15.3 \%$ \\
\hline Textiles & $0.6 \%$ & $5.9 \%$ & $-0.4 \%$ & $1.7 \%$ & $2.7 \%$ \\
\hline Textiles, garment and apparel & $0.5 \%$ & $5.8 \%$ & $-1.0 \%$ & $1.3 \%$ & $1.6 \%$ \\
\hline $\begin{array}{l}\text { Leather, fur, feathers and their products and } \\
\text { footwear }\end{array}$ & $-0.6 \%$ & $5.9 \%$ & $-0.3 \%$ & $0.2 \%$ & $0.7 \%$ \\
\hline $\begin{array}{l}\text { Wood processing and wood, bamboo, rattan, } \\
\text { palm and grass products }\end{array}$ & $1.7 \%$ & $6.5 \%$ & $6.2 \%$ & $0.1 \%$ & $3.5 \%$ \\
\hline Furniture manufacturing & $1.1 \%$ & $5.9 \%$ & $-1.7 \%$ & $3.5 \%$ & $2.7 \%$ \\
\hline Paper making and paper products & $0.9 \%$ & $6.1 \%$ & $1.4 \%$ & $-0.3 \%$ & $2.8 \%$ \\
\hline Printing and recording medium reproduction & $1.2 \%$ & $5.9 \%$ & $1.7 \%$ & $-0.3 \%$ & $2.7 \%$ \\
\hline $\begin{array}{l}\text { Culture and education, arts and crafts, sports and } \\
\text { entertainment products manufacturing }\end{array}$ & $4.4 \%$ & $5.9 \%$ & $4.4 \%$ & $0.1 \%$ & $6.3 \%$ \\
\hline Petroleum, coal and other fuel processing & $0.0 \%$ & $10.0 \%$ & $0.0 \%$ & $0.0 \%$ & $10.0 \%$ \\
\hline $\begin{array}{l}\text { Chemical raw materials and products } \\
\text { manufacturing }\end{array}$ & $1.5 \%$ & $7.0 \%$ & $1.0 \%$ & $0.6 \%$ & $4.5 \%$ \\
\hline Pharmaceutical manufacturing & $0.0 \%$ & $6.6 \%$ & $-0.6 \%$ & $0.0 \%$ & $1.7 \%$ \\
\hline Chemical fiber manufacturing & $-1.5 \%$ & $7.8 \%$ & $1.0 \%$ & $-2.4 \%$ & $1.9 \%$ \\
\hline Rubber and plastic manufacturing & $1.0 \%$ & $6.1 \%$ & $-0.7 \%$ & $1.2 \%$ & $2.8 \%$ \\
\hline Non-metallic minerals manufacturing & $1.2 \%$ & $6.7 \%$ & $-1.1 \%$ & $1.4 \%$ & $3.3 \%$ \\
\hline Ferrous metal smelting and rolling processing & $0.2 \%$ & $12.5 \%$ & $-0.5 \%$ & $0.5 \%$ & $12.1 \%$ \\
\hline $\begin{array}{l}\text { Non-ferrous metal smelting and rolling } \\
\text { processing }\end{array}$ & $2.0 \%$ & $6.7 \%$ & $1.8 \%$ & $0.3 \%$ & $5.3 \%$ \\
\hline Metal products manufacturing & $0.3 \%$ & $6.0 \%$ & $-1.3 \%$ & $1.5 \%$ & $2.6 \%$ \\
\hline General equipment manufacturing & $0.8 \%$ & $6.6 \%$ & $0.1 \%$ & $0.8 \%$ & $3.0 \%$ \\
\hline Special equipment manufacturing & $2.2 \%$ & $6.1 \%$ & $0.7 \%$ & $0.9 \%$ & $3.8 \%$ \\
\hline Transportation equipment manufacturing & $0.1 \%$ & $7.3 \%$ & $0.7 \%$ & $-0.1 \%$ & $3.2 \%$ \\
\hline $\begin{array}{l}\text { Electrical machinery and equipment } \\
\text { manufacturing }\end{array}$ & $1.2 \%$ & $6.6 \%$ & $-0.4 \%$ & $1.5 \%$ & $3.3 \%$ \\
\hline $\begin{array}{l}\text { Computer, communications and other electronic } \\
\text { equipment manufacturing }\end{array}$ & $3.8 \%$ & $8.7 \%$ & $1.3 \%$ & $2.3 \%$ & $7.8 \%$ \\
\hline Manufacturing aggregate & $0.9 \%$ & $7.2 \%$ & $0.5 \%$ & $0.6 \%$ & $4.3 \%$ \\
\hline
\end{tabular}

Note: EC, TC, PEC, SEC, TFP respectively represent technical efficiency, technological progress, pure technical efficiency, scale efficiency and TFP change (the same below). 
Table 2. Average TFP growth of 26 manufacturing sub-industries in various provinces in 2006-2018

\begin{tabular}{|c|c|c|c|c|c|c|}
\hline Industry Province & Shandong & Guangdong & Jiangsu & Zhejiang & Anhui & Shanghai \\
\hline Non-staple food processing & $2.35 \%$ & $1.04 \%$ & $4.00 \%$ & $-1.77 \%$ & $5.66 \%$ & $-0.49 \%$ \\
\hline Food manufacturing & $3.30 \%$ & $3.36 \%$ & $6.37 \%$ & $-2.61 \%$ & $18.21 \%$ & $2.22 \%$ \\
\hline $\begin{array}{l}\text { Liquor, beverage and refined tea } \\
\text { manufacturing }\end{array}$ & $2.24 \%$ & $2.44 \%$ & $-0.38 \%$ & $-1.14 \%$ & $7.71 \%$ & $-1.79 \%$ \\
\hline Tobacco processing & $7.90 \%$ & $6.12 \%$ & $12.03 \%$ & $14.04 \%$ & $0.32 \%$ & $12.25 \%$ \\
\hline Textiles & $6.37 \%$ & $4.32 \%$ & $2.80 \%$ & $1.14 \%$ & $7.34 \%$ & $2.28 \%$ \\
\hline Textiles, garment and apparel & $0.55 \%$ & $2.65 \%$ & $1.92 \%$ & $-0.87 \%$ & $8.18 \%$ & $-0.76 \%$ \\
\hline $\begin{array}{l}\text { Leather, fur, feathers and their } \\
\text { products and footwear }\end{array}$ & $-1.24 \%$ & $3.77 \%$ & $5.97 \%$ & $0.24 \%$ & $2.91 \%$ & $-3.50 \%$ \\
\hline $\begin{array}{l}\text { Wood processing and wood, } \\
\text { bamboo, rattan, palm and grass } \\
\text { products }\end{array}$ & $4.90 \%$ & $3.29 \%$ & $6.51 \%$ & $-2.47 \%$ & $9.01 \%$ & $-0.12 \%$ \\
\hline Furniture manufacturing & $4.28 \%$ & $1.18 \%$ & $5.25 \%$ & $1.17 \%$ & $11.11 \%$ & $-1.12 \%$ \\
\hline Paper making and paper products & $1.11 \%$ & $3.01 \%$ & $4.50 \%$ & $3.21 \%$ & $6.08 \%$ & $0.64 \%$ \\
\hline $\begin{array}{l}\text { Printing and recording medium } \\
\text { reproduction }\end{array}$ & $7.95 \%$ & $4.15 \%$ & $4.51 \%$ & $3.11 \%$ & $7.74 \%$ & $2.16 \%$ \\
\hline $\begin{array}{l}\text { Culture and education, arts and } \\
\text { crafts, sports and entertainment } \\
\text { products manufacturing }\end{array}$ & $3.27 \%$ & $2.22 \%$ & $2.76 \%$ & $2.23 \%$ & $7.67 \%$ & $3.46 \%$ \\
\hline $\begin{array}{l}\text { Petroleum, coal and other fuel } \\
\text { processing }\end{array}$ & $6.41 \%$ & $6.94 \%$ & $2.93 \%$ & $-0.62 \%$ & $5.16 \%$ & $4.64 \%$ \\
\hline $\begin{array}{l}\text { Chemical raw materials and } \\
\text { products manufacturing }\end{array}$ & $2.05 \%$ & $1.49 \%$ & $3.38 \%$ & $0.45 \%$ & $3.95 \%$ & $2.84 \%$ \\
\hline Pharmaceutical manufacturing & $2.51 \%$ & $-0.35 \%$ & $3.65 \%$ & $-1.65 \%$ & $8.81 \%$ & $0.49 \%$ \\
\hline Chemical fiber manufacturing & $5.23 \%$ & $3.13 \%$ & $0.60 \%$ & $-1.01 \%$ & $3.22 \%$ & $-0.58 \%$ \\
\hline Rubber and plastic manufacturing & $-1.04 \%$ & $0.85 \%$ & $1.33 \%$ & $0.04 \%$ & $6.85 \%$ & $1.17 \%$ \\
\hline $\begin{array}{l}\text { Non-metallic minerals } \\
\text { manufacturing }\end{array}$ & $3.19 \%$ & $3.20 \%$ & $5.32 \%$ & $5.04 \%$ & $8.32 \%$ & $0.76 \%$ \\
\hline $\begin{array}{l}\text { Ferrous metal smelting and rolling } \\
\text { processing }\end{array}$ & $0.61 \%$ & $3.98 \%$ & $2.08 \%$ & $4.53 \%$ & $7.22 \%$ & $4.54 \%$ \\
\hline $\begin{array}{l}\text { Non-ferrous metal smelting and } \\
\text { rolling processing }\end{array}$ & $4.46 \%$ & $3.38 \%$ & $0.19 \%$ & $3.51 \%$ & $7.56 \%$ & $0.78 \%$ \\
\hline Metal products manufacturing & $2.17 \%$ & $2.05 \%$ & $2.10 \%$ & $1.18 \%$ & $4.17 \%$ & $-0.33 \%$ \\
\hline General equipment manufacturing & $2.08 \%$ & $1.35 \%$ & $0.95 \%$ & $-0.23 \%$ & $6.18 \%$ & $-0.17 \%$ \\
\hline Special equipment manufacturing & $1.13 \%$ & $1.20 \%$ & $2.30 \%$ & $-0.15 \%$ & $8.52 \%$ & $-0.07 \%$ \\
\hline $\begin{array}{l}\text { Transportation equipment } \\
\text { manufacturing }\end{array}$ & $0.89 \%$ & $1.98 \%$ & $3.59 \%$ & $-1.46 \%$ & $3.69 \%$ & $3.23 \%$ \\
\hline $\begin{array}{l}\text { Electrical machinery and equipment } \\
\text { manufacturing }\end{array}$ & $-2.18 \%$ & $-1.07 \%$ & $2.26 \%$ & $-0.72 \%$ & $3.10 \%$ & $0.05 \%$ \\
\hline $\begin{array}{l}\text { Computer, communications and } \\
\text { other electronic equipment } \\
\text { manufacturing }\end{array}$ & $2.16 \%$ & $-0.70 \%$ & $1.54 \%$ & $-1.25 \%$ & $2.50 \%$ & $0.44 \%$ \\
\hline Manufacturing aggregate & $3.01 \%$ & $2.65 \%$ & $3.49 \%$ & $0.92 \%$ & $6.58 \%$ & $1.27 \%$ \\
\hline
\end{tabular}

Note: industries related to electronic information product manufacturing include computer, communication and other electronic equipment manufacturing; automobile manufacturing related industries are transportation equipment manufacturing; industries related to petrochemical and fine chemical manufacturing include petroleum, coal and other fuel processing, and chemical raw materials and products manufacturing; industries related to high-quality steel manufacturing are ferrous metal smelting and rolling processing; industries related to complete equipment manufacturing include general equipment manufacturing and special equipment manufacturing; industries related to biomedicine manufacturing are pharmaceutical manufacturing. 
Table 3. Average TFP growth of six pillar sub-industries in Shanghai and its decompositions from 2002 to 2018

\begin{tabular}{|c|c|c|c|c|c|}
\hline Industry & $\mathbf{E C}$ & TC & PEC & SEC & TFP \\
\hline Electronic information product manufacturing & $0.1 \%$ & $3.8 \%$ & $0.0 \%$ & $0.1 \%$ & $3.7 \%$ \\
\hline Automobile manufacturing & $-0.7 \%$ & $7.3 \%$ & $0.6 \%$ & $-1.3 \%$ & $5.6 \%$ \\
\hline $\begin{array}{l}\text { Petrochemical and fine chemical } \\
\text { manufacturing }\end{array}$ & $0.8 \%$ & $6.5 \%$ & $0.7 \%$ & $0.1 \%$ & $7.1 \%$ \\
\hline High-quality steel manufacturing & $0.0 \%$ & $11.9 \%$ & $0.0 \%$ & $0.0 \%$ & $11.9 \%$ \\
\hline Complete equipment manufacturing & $-1.1 \%$ & $5.1 \%$ & $-0.1 \%$ & $-0.9 \%$ & $3.3 \%$ \\
\hline Biomedicine manufacturing & $-2.1 \%$ & $4.4 \%$ & $0.0 \%$ & $-2.1 \%$ & $1.6 \%$ \\
\hline Average of six industries & $-0.50 \%$ & $6.50 \%$ & $0.20 \%$ & $-0.68 \%$ & $5.53 \%$ \\
\hline Manufacturing as a whole & $-1.3 \%$ & $7.8 \%$ & $-0.2 \%$ & $-0.7 \%$ & $3.3 \%$ \\
\hline
\end{tabular}

\section{Copyrights}

Copyright for this article is retained by the author(s), with first publication rights granted to the journal.

This is an open-access article distributed under the terms and conditions of the Creative Commons Attribution license (http://creativecommons.org/licenses/by/4.0/). 